\title{
Independent Regulation of Multiple Output Flyback Converter with Pulse-Train Control
}

\author{
Guo Xiao-ying ${ }^{1}$, Liu Wei ${ }^{2}$, Cao Tai-qiang ${ }^{2}$, Li Jia-hui ${ }^{3}$ and Luo Qian ${ }^{4}$ \\ ${ }^{1}$ School of Information and Electric Engineering, Panzhihua University, \\ Panzhihua 617000, Sichuan, China \\ ${ }^{2}$ School of Electrical Engineering and Electronic Information, Xihua University, \\ Chengdu 610039, China \\ ${ }^{3}$ School of Information Engineering, Southwest University of Science and \\ Technology, Mianyang Sichuan 621010, China \\ ${ }^{4}$ The Second Research Institute of CAAC ChengDu 610041 China \\ 25971025@qq.com
}

\begin{abstract}
A family of independent-regulation multiple-output (IRMO) dc-dc flyback converters was researched in this paper, and its control in discontinuous conduction mode (DCM) was achieved by using pulse-train (PT) control method. To avoid cross-regulation between each output of multiple output flyback converters, time-multiplexing scheme is used to determine which output is controlled in the time interval of time-multiplexing signal. Error amplifier and corresponding compensators as required by conventional pulse width modulation (PWM) technique were not used in PT control. The multiple output flyback converters with PT control proposed in this paper is simple and enjoys fast dynamic response. It can achieve constant voltage output, and can also achieve constant current output, which provides an effective solution for multiple constant current output application, especially in LED backlight application.
\end{abstract}

Keywords: Independent-regulation multiple-output, pulse train control technique, timing-multiplexing, discontinuous conduction mode, LED backlight

\section{Introduction}

Isolated multiple independent outputs of power supply are usually required by equipment and devices such as LED backlight system, power adapter device and so on. Development of low cost and uncrossed regulation multiple output power supplies has thus attracted much attention recently [1]. Using $\mathrm{N}$ different switching converters is the most straightforward implementation [2]. However, this method requires too many components, including controllers and power devices, thus increase system complexity and cost. If it is not required to control $\mathrm{N}$ different outputs individually, a transformer with one primary winding and $\mathrm{N}$ secondary windings could be used. But this solution cannot control individual outputs precisely [3],Single-inductor multiple-output (SIMO) converter with only one inductor benefits in significant overall cost saving, small size and light weight of equipment and device, which make it as one of the most suitable and costeffective solution for multiple output power supplies [6]. But research is focus on the topology and control method in non-isolated application.

In this paper, a family of independent-regulation multiple-output (IRMO) dc-dc flyback converters was researched, and its control in discontinuous conduction mode (DCM) was achieved by using PT control method. "Blank pulse" is adopted to improve its transient performance and light load efficiency. The time-multiplexing scheme is adopted for the control of IRMO flyback converter in DCM to prevent cross-regulation 
between each output. PT control IRMO flyback converters, which can achieve constant voltage output, and can also achieve constant current output, provides an effective solution for multiple constant current output application, especially in LED backlight application.

\section{Independent Regulation of Multiple Output Flyback Converters}

Considering two conventional flyback converters switching at a frequency of $f_{\mathrm{s}}(=1 / T)$ and working in DCM with duty ratios $D_{1 \mathrm{a}}$ and $D_{1 \mathrm{~b}}$, the schematics and waveforms of their inductor currents are shown in Figure 1. For converter A, the inductor current ramps up during $D_{1 \mathrm{a}} \mathrm{T}$, ramps down during $D_{2 \mathrm{a}} T$, and stays zero during $\mathrm{D}_{3 \mathrm{a}} T$, which is similar to the characteristics of converter B. If $D_{1 \mathrm{a}}+D_{2 \mathrm{a}}<0.5$ and $D_{1 \mathrm{~b}}+D_{2 \mathrm{~b}}<0.5$, the two converters can be operated in complementary phases $\Phi_{\mathrm{a}}$ and $\Phi_{\mathrm{b}}$. And then, two independent flyback converters can be combined into an independent-regulation dual-output (IRDO) flyback converter which has a single magnetic element as shown in Figure 2. Using timemultiplexing (TM) scheme [8], each output of this flyback converter can be regulated independently. When $S_{o a}=1$, output A will be regulated, when $S_{o b}=1$, output B will be regulated [9-13].

Time multiplexing can be extended to multiple $(N)$ outputs, and each output should occupy a time slot of $T / N$ for charging and discharging the inductor.

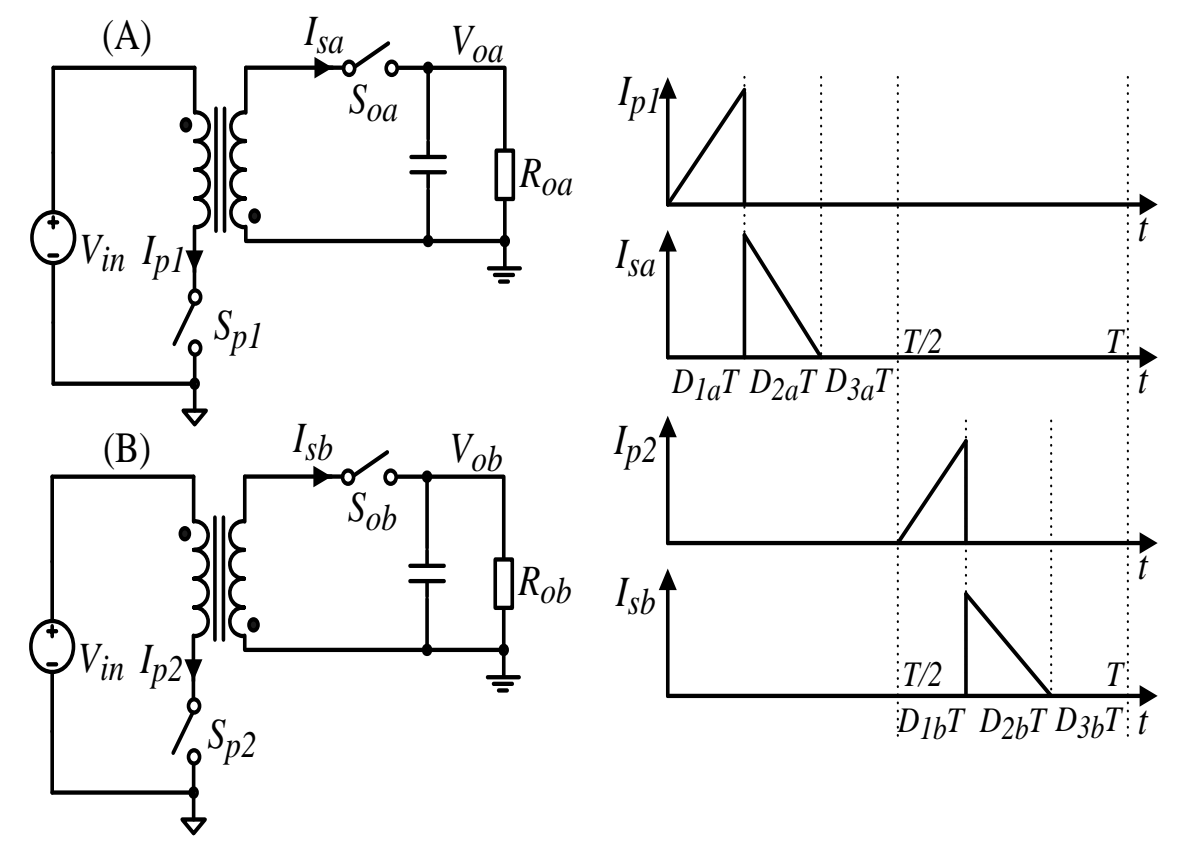

Figure 1. Two Independent Regulated Flyback Converters and their Switching Current in DCM 

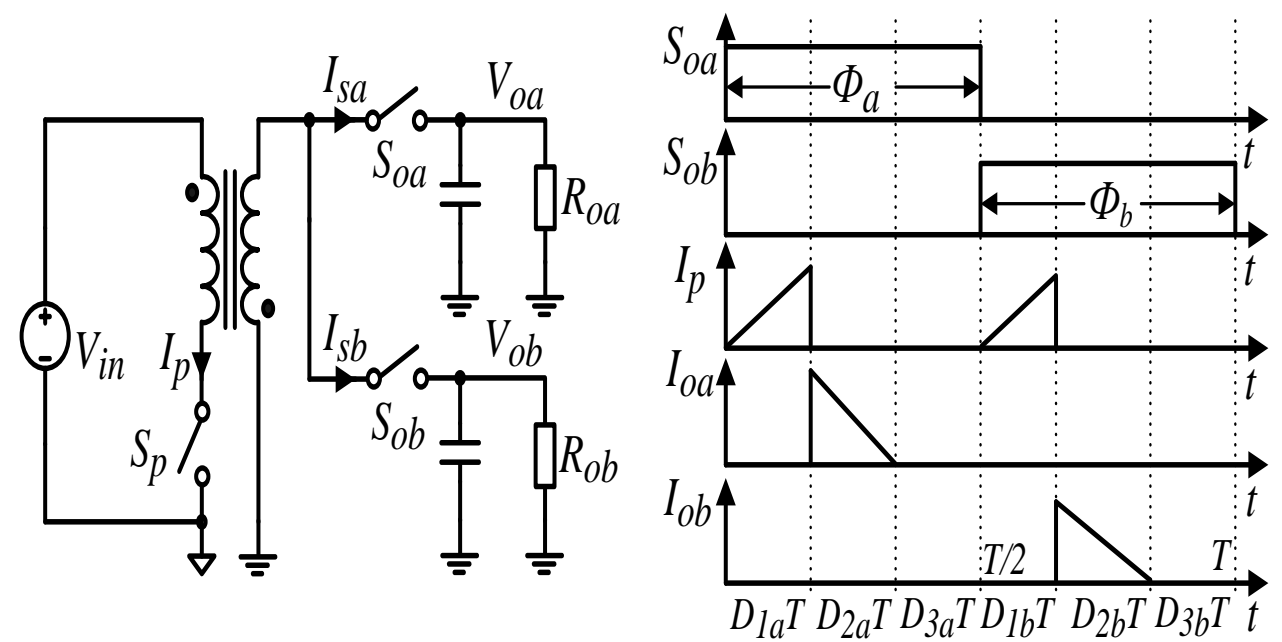

Figure 2. Independent Regulated Dual Output Flyback Converter and It's Switching Current in DCM

\section{PT Control of IRDO Flyback Converter}

The block diagram of the proposed PT control IRDO flyback converter operating in DCM is shown in Figure 3 and its corresponding timing diagrams are shown in Figure 4 High-power pulse, low-power pulse and blank pulse are selected as active control signals of power switch according to the relation between output voltage and reference voltage.

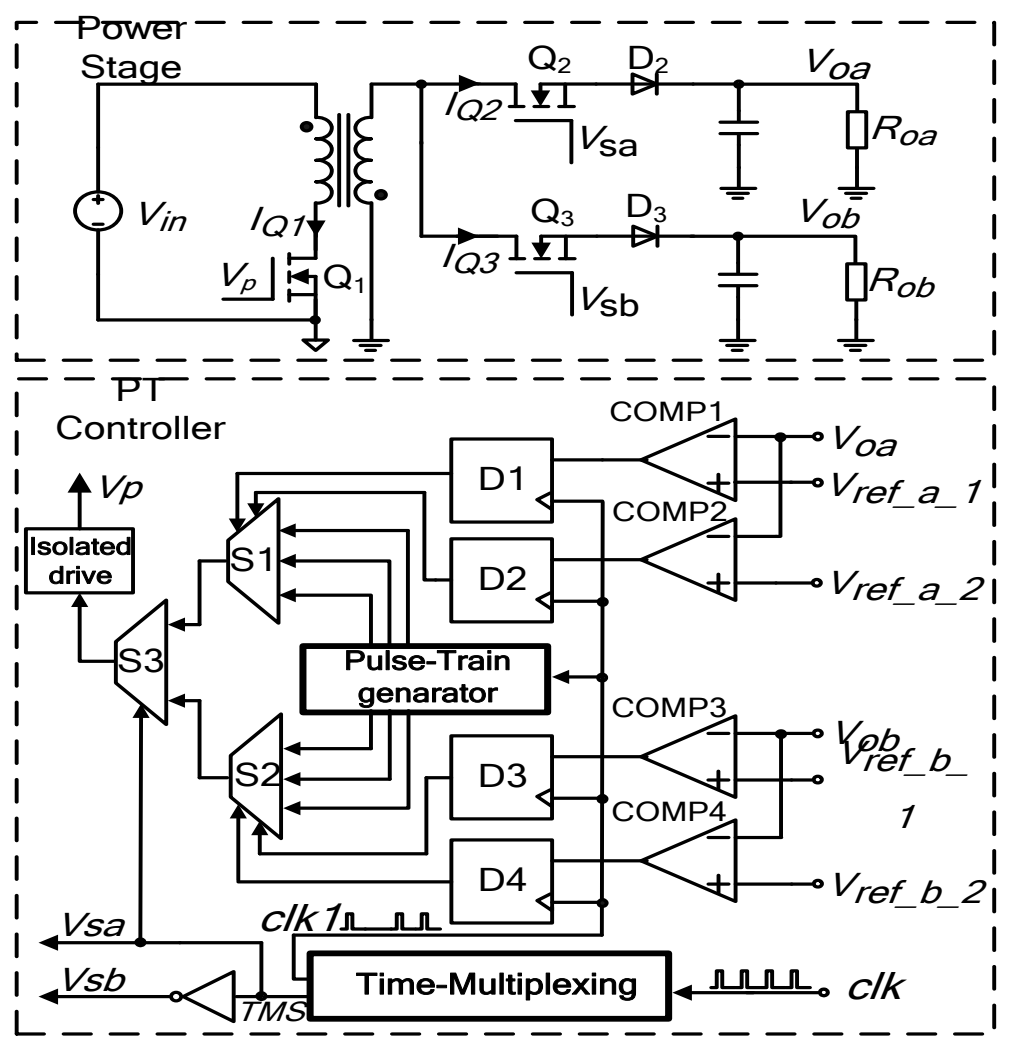

Figure 3. Block Diagram of Proposed Voltage-Mode PT Control IRDO Flyback Converter 
The TM control signal TMS in Figure 4 is used to determine which output is controlled. When $T M S=1$, the output voltage $V_{\text {оа }}$ is regulated, and when $T M S=0$, the output voltage $V_{o b}$ is regulated.

Figure 4 show the timing diagram of IRDO flyback converter when $T_{\mathrm{A}} / T_{\mathrm{B}}=1$, where TA is the control time of output A in a switching period, and TB is the control time of output $\mathrm{B}$ in a switching period. The ratio of $T_{\mathrm{A}}$ to $T_{\mathrm{B}}$ is determined by the ratio of maximum power of each output, and applying the maximum power of each output to determine $T_{\mathrm{A}} / T_{\mathrm{B}}$ can improve the utilization rate of inductor [8].

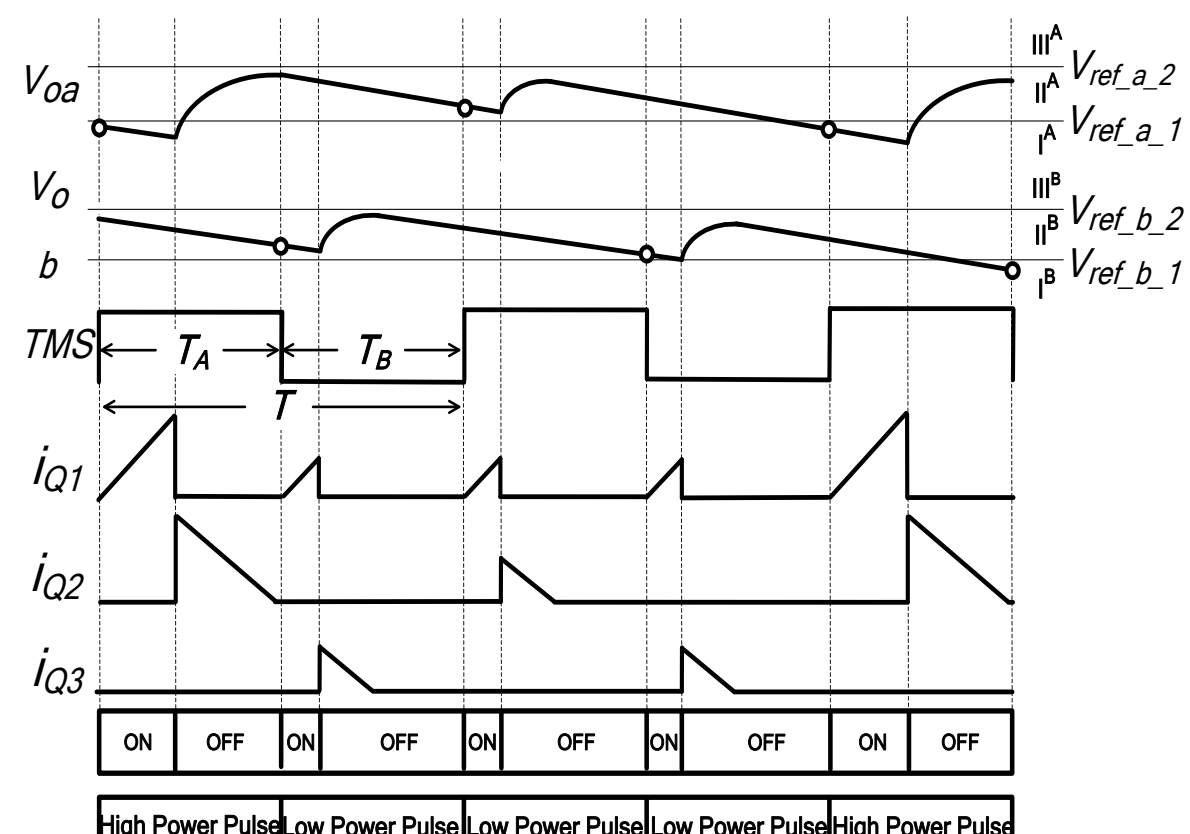

Figure 4. Sequence Diagram of SIDO Buck Converter with Time-Multiplexing Voltage Mode PT Control $\left(T_{A} / T_{B}=1\right)$

By using two predefined reference voltage $\mathrm{V}_{\text {ref_a_ }} 1$ and $V_{\text {ref_a_2 }}\left(V_{\text {ref_a_1 }}<V_{\text {ref_a_2 }}\right)$, the output voltage $V_{\text {oa }}$ is divided into three regions $\mathrm{I}^{\mathrm{A}}, \mathrm{II}^{\mathrm{A}}$ and $\mathrm{III}^{\mathrm{A}}$. These two predefined reference voltage must ensure that the output voltage is regulated within the tolerance.

In the region IA, $V_{\text {oa }}$ is lower than the reference voltage $V_{\text {ref_a_ } 1}$. Hence, high-power pulse is needed to deliver more power to the load to make output voltage increase. During the high power pulse, the energy drawn from the input power source is

$$
\Delta E_{i n_{-} H_{-} A}=\frac{V_{i n}^{2} T^{2}}{2 L_{p}} D_{1 a_{-} H}{ }^{2}
$$

In the region $\mathrm{II}^{\mathrm{A}}, V_{\text {oa }}$ is higher than the reference voltage $V_{\text {ref_a_ } 1}$, but lower than the

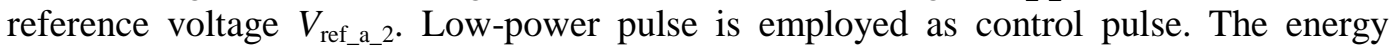
drawn from the input power source during low-power pulse is

$$
\Delta E_{i n_{-} L_{-} A}=\frac{V_{i n}^{2} T^{2}}{2 L_{p}} D_{1 a_{-} L}^{2}
$$

If the load is lighter than the power providing by a low power pulse, $V_{\text {oa }}$ will increase to the region $\mathrm{III}^{\mathrm{A}}$. Blank pulse is employed to discharge the output filter capacitor. The controller enters skipping-cycle mode controlled by the combination of low-power pulses and blank pulses. The number of the skipping-cycle increases with the decreasing of the load. 
From the above analysis we can conclude that the duty ratio of high-power pulse $D_{\mathrm{H}}$ determines the maximum power of output A. The duty ratio of low-power pulse $D_{\mathrm{L}}$ determines the maximum load power of skipping-cycle mode. When the output $\mathrm{A}$ is under heavy load, the minimum value of $V_{\text {oa }}$ will fall in the region $\mathrm{I}^{\mathrm{A}}$ or $\mathrm{II}^{\mathrm{A}}$. With the decreasing of the load, the minimum value of $V_{\text {oa }}$ will increase to III ${ }^{\mathrm{A}}$.

It is the same for the regulation of output voltage $V_{\mathrm{ob}}$. When the converter operates in DCM, the charging time of lower power pulse on the inductor is less than high-power pulse. The pulse train pattern can be set as low-power pulse and blank pulse if the maximum power of output B can be satisfied by the combination of low-power pulse and blank pulse, thus the operating time тв can be decreased. Therefore, we can increase the maximum power of output $A$. This method can improve the utilization rate of inductor, while the load power of output $B$ is satisfied.

In DCM, a continuous high power pulse train can achieve the voltage gain $M_{\mathrm{a}}$ of output A as

$$
M_{a}=\frac{V_{o a}}{V_{i n}}=\frac{D_{1 a_{-} H}}{N D_{2 a_{-} H}}
$$

Where, $D_{1 \mathrm{a} \_\mathrm{H}}$ and $D_{2 \mathrm{a} \_\mathrm{H}}$ are the duty ratios of inductor current rise and fall time respectively of output A. During the operating time $T_{\mathrm{A}}$, in order to make sure the inductor current operating in DCM, the value of $D_{1 a_{-} \mathrm{H}}$ must be lower than

$$
D_{1 a_{-} H_{-} \max }=\frac{N V_{o a} D_{A}}{V_{i n}+N V_{o a}}
$$

Where, $D_{\mathrm{A}}$ is the duty ratio of output A multiplexing time in one switching cycle. Similarly, in order to make sure the inductor current operating in DCM, the value of $D_{1 \mathrm{~b} \_\mathrm{H}}$ must be lower than

$$
D_{1 b_{-} H_{-} \max }=\frac{N V_{o a}\left(1-D_{A}\right)}{V_{i n}+N V_{o b}}
$$

According to (4), the maximum output power of output $\mathrm{A}$ is

$$
P_{o a_{-} \max }=\frac{V_{i n}^{2} T D_{1 a_{-} H_{-} \text {max }}^{2}}{2 L_{p}}
$$

Correspondingly, the maximum output power of output B is

$$
P_{o b_{-} \text {max }}=\frac{V_{i n}^{2} T D_{1 b_{-} H_{-} \text {max }}^{2}}{2 L_{p}}
$$

If the voltage of output $\mathrm{A}$ is the same as output $\mathrm{B}$, the relationship between maximum output power of each output and $D_{\mathrm{A}}$ is shown in Figure 6. The less multiplexing time of each road can be used, the less power of each road can output. When $D_{\mathrm{A}}=0.5$, the total output power of the converter reaches to the minimum value. 


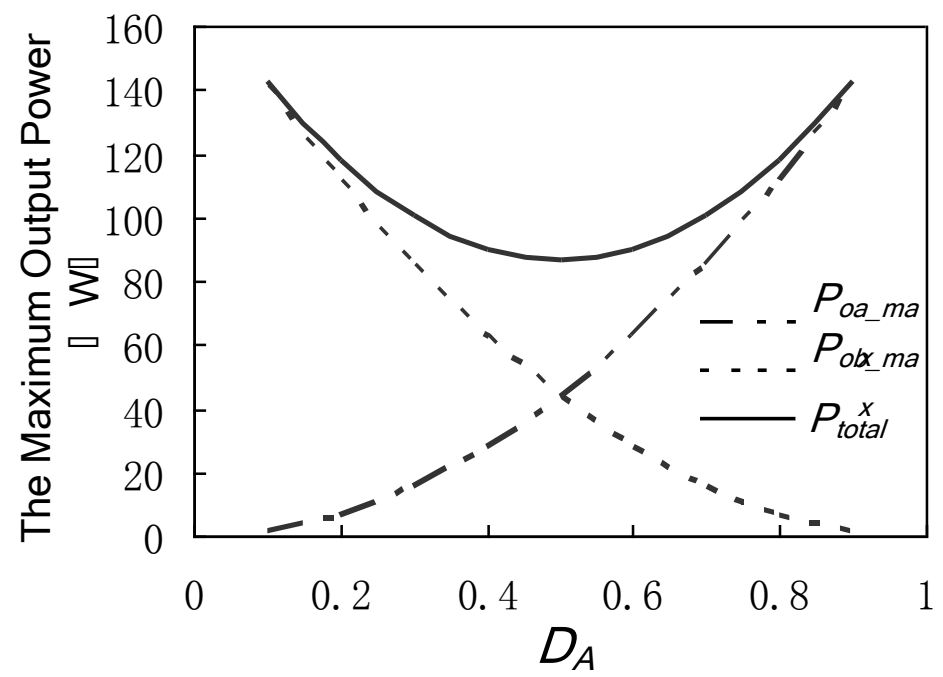

Figure 5. The Relationship between Maximum Output Power of Each Output and DA

\section{Conclusion}

In this paper, a family of isolated IRMO dc-dc flyback converters was researched, and used flyback converter as an example to achieve its control in DCM by using PT control method. The time-multiplexing scheme is adopted for the control of IRMO flyback converter in DCM to prevent cross-regulation between each output. PT control IRMO flyback converters, which can achieve constant voltage output and also can achieve constant current output, provide an effective solution for multiple constant current output application. Besides the simplicity of design and uncrossed regulation, this control method enjoys a fast dynamic response.

\section{Acknowledgments}

This work was Supported by the Sichuan Province High School Key Lab-Solar Energy Integration and Application Promotion(2013TYNZ-02); Panzhihua Intelligent Solar Energy Disconnection/Connection Control System(2014CY-S-1-2); Distributed Photovaltaic Multi-inverter Connection Control Program(2014YB11); Plan Technology Program of Panzhihua(2015 CY-C-5) ; Supported by the Open Research Subject of Sichuan Province Key Laboratory of Power Electronics Energy-saving Technologies \& Equipment(szjj2015-066).

\section{References}

[1] X. Liu, J. Xu and J. Wang, "A single-inductor dual-output buck converter with pulse-train control[C]//Power Electronics for Distributed Generation Systems (PEDG), 2010 2nd IEEE International Symposium on. IEEE, (2010), pp. 449-452.

[2] Z. Shen, X. Chang and W. Wang, "Predictive digital current control of single-inductor multipleoutput converters in ccm with low cross regulation [J]", Power Electronics, IEEE Transactions on, vol. 27, no. 4, (2012), pp. 1917-1925.

[3] J. Xu and J. Wang. "Bifrequency pulse-train control technique for switching DC-DC converters operating in DCM." Industrial Electronics, IEEE Transactions on 58.8, (2011), pp. 3658-3667.

[4] J. Wang and J. Xu. "Peak current mode bifrequency control technique for switching DC-DC converters in DCM with fast transient response and low EMI." Power Electronics, IEEE Transactions on 27.4, (2012), pp. 1876-1884. 
[5] Y. Zhang and D. Ma, "Adaptive pseudo-continuous conduction mode operation schemes and circuit designs for single-inductor multiple-output switching converters [J]", Analog Integrated Circuits and Signal Processing, vol. 72, no. 2, (2012), pp. 419-432.

[6] C. Chae, H. Le, K. Lee, "A Single-Inductor Step-Up DC-DC Switching Converter with Bipolar Outputs for Active Matrix OLED Mobile Display Panels", IEEE Journal of Solid State Circuits, vol.44, no.2, (2009), pp.509-524.

[7] Z. Shen, X. Chang, W. Wang, "Predictive digital current control of single-inductor multipleoutput converters in ccm with low cross regulation [J]", Power Electronics, IEEE Transactions on, vol. 27, no. 4, (2012), pp. 1917-1925.

[8] X. Liu, "A single-inductor dual-output buck converter with pulse-train control." Power Electronics for Distributed Generation Systems (PEDG), 2010 2nd IEEE International Symposium on. IEEE, (2010).

[9] H. Li, B. Zhang and P. Luo, "Adaptive duty ratio modulation technique in switching DC-DC converter operating in discontinuous conduction mode [J]," Analog Integrated Circuits and Signal Processing, (2013), pp. 1-11.

[10] M. Salimi, J. Soltani and G.A. Markadeh, Indirect output voltage regulation of DC-DC buck/boost converter operating in continuous and discontinuous conduction modes using adaptive back stepping approach [J]. IET Power Electronics, vol. 6, no. 4, (2013), pp. 732-741.

[11] Y. Ko, Y. Jang and S.K. Han, "A Fast Low Dropout Regulator with High Slew Rate and Large Unity-Gain Bandwidth", Journal of Semiconductor Technology and Science, vol. 13, no. 4, (2013), pp. 263-271.

[12] C. Restrepo, J. Calvente and A. Cid-Pastor, A noninverting buck-boost DC-DC switching converter with high efficiency and wide bandwidth", Power Electronics, IEEE Transactions on, vol. 26, no, 9, (2011), pp. 2490-2503.

[13] J. Xu and M. Qin, "Multi pulse train control technique for buck converter in discontinuous conduction mode", IET Power Electronics, vol. 3, no. 3, (2010), pp. 391-399. 
International Journal of Control and Automation Vol.9, No.1 (2016) 